\title{
Homemade versus Commercial Jarred Baby Foods with Regard to Nitrites and Nitrates Content
}

\author{
Anna Bona \\ Poznan University of Economics and Business, Department of Food Commodity Science, Poznan 61-875, Poland
}

\begin{abstract}
This paper presents results of nitrites and nitrates determination in two types of baby foods: commercial products in jars and their homemade conventional counterparts. Nitrites levels in all analyzed samples were below of the detection limit $(<0.9 \mathrm{mg} / \mathrm{kg})$ of applied spectrophotometric method with Griess reagent. Nitrates contents in commercial products ranged: 9.1-38.1 mg/kg while in homemade baby foods levels between $26.6 \mathrm{mg} / \mathrm{kg}$ and $118.8 \mathrm{mg} / \mathrm{kg}$ were obtained. All the contents of nitrates were lower than the EU legislation maximum limit $(200 \mathrm{mg} / \mathrm{kg}$ ). Comparison of each type of commercial product with its homemade counterpart baby food evidenced significant differences $(p<0.05)$ in average nitrates levels in favor of the first type. Apart from determining and comparing the levels of nitrates in the baby food samples also risk assessment for an average 6-months old infant to nitrates exposure was conducted. The estimated nitrates intake with a typical portion of $200 \mathrm{~g}$ of baby food ranged between $6 \%$ and $25.7 \%$ of acceptable daily intake for commercial and from $18.0 \%$ to $80.3 \%$ for homemade ones.
\end{abstract}

Key words: Nitrites, nitrates, baby food, food safety, weaning, infants.

\section{Introduction}

Optimal kind of complementary foods during the first year of life has always been common subject of discussion. Nutrition practices differ in many countries, however according to WHO weaning should start at the age of 6 months to cover infant's nutritional needs and get used to solids [1]. During this transition period children are particularly vulnerable. Dietary exposure to chemical hazards of an infant tends to be even three times that of an adult. Both composition and consumption pattern of baby foods are important. Complementary meals may be either self-prepared or bought as ready-to-eat products. Quality of commercial baby foods is regulated in EC guideline [2]. In turn, composition and preparation of homemade meals is parents' responsibility. Nutrition specialists provide recipes for complementary food, nevertheless there are no studies available how parents use them [3]. Commercial products are thought to be safe and nutritious alternatives instead of self-prepared

Corresponding author: Anna Bona, Ph.D., research field: food commodity science. meals. However, several harmful substances originating from the nature of the product's ingredients may be present. Consequently assessment of dietary exposure to contaminants in baby foods is needed to ensure healthy growth of infants.

Reports regarding serious effects for infants connected to nitrates and nitrites consumption with food are available. Nitrates and nitrites ions may cause many physiologic effects including hematological, cardiovascular and respiratory outcomes [4, 5]. Therefore, the interest in its determination in baby meals is of great importance because of its possible exposure route through different foodstuff prepared at home or bought as commercial baby food.

Current women's lifestyle, convenience and legislatively guaranteed quality of commercial baby foods encourage mothers to buy them to a large extent. Great percentage of women declares using this kind of products but when asked about preferences towards the kind of complementary food they rather show willingness to home prepared traditional meals. It reveals lack of their real conviction in weaning food choices and need of carrying research of the both 
types of meals. Mothers of infants are strongly interested in evidence, which could help to clear their doubts concerning choice of complementary baby foods [6]. Little available information is to confirm any opinion: about superiority of homemade over commercial baby foods or inverse.

Recent studies on nitrates and nitrites contents represent outcomes only commercial baby foods without taking into consideration home-prepared ones [7-10]. There is a lack of data concerning comparison of commercial and equivalent homemade weaning meals.

This research presents comparison of ready-to-eat baby foods in jars with their homemade counterparts on the basis of nitrates and nitrites content and assessment whether at the beginning of weaning period the use of any type of meal could be a cause of safety concern.

\section{Materials and Methods}

\subsection{Selection of Material}

The most responsible sources of infants' dietary intake of nitrates are vegetables and drinking water [11]. Vegetable and vegetable-meat products were researched. Homemade meals were prepared with components bought in popular groceries in western Poland-in Poznan city. Commercial baby foods were purchased in the same shops. Ready-to-eat foods in jars constituted five types of the most popular products indicated by mothers in previous study concerning their preferences towards complementary foods in jars [6]. Recipes of homemade meals derived from infant feeding guides. Selection of recipes aimed to remind composition of preferred jarred foods as much as possible. To the current knowledge, no studies are available on how caregivers use complementary meal recipes at home. The assumption was made to self cook the meals for assurance that they reflect chosen recipes of the greatest. Conducted study apparently shows a very realistic and most probably common case when decision to choose type of a meal is taken among easily accessible products without searching for any special variants of ingredients or preparation methods.

Shelf life of commercial baby foods was maximum 24 months. Nevertheless this long term usefulness should not affect nitrates content for the reason that products were previously intended to thermal preservation and tight seal. Home-prepared meals were made right before the research to restrain changes of nitrates contents during storage.

Table 1 presents composition of all the meals. Samples "C" (commercial) and "H" (homemade) indicated with the same number constitute each other's counterparts in nitrates content comparison.

\subsection{Nitrites and Nitrates Determination Method}

The spectrophotometric method according to the

Table 1 Composition of meals purposed for nitrates and nitrites content determination (C-commercial, H-homemade baby foods).

\begin{tabular}{|c|c|c|c|}
\hline $\mathrm{C}$ & $\begin{array}{l}\text { Composition of commercial baby foods } \\
\text { (labels of jarred baby foods) }\end{array}$ & $\mathrm{H}$ & $\begin{array}{l}\text { Composition of homemade baby foods } \\
\text { (www.parenting.pl; infant nutrition guides) }\end{array}$ \\
\hline C1 & $\begin{array}{l}\text { carrot } 39.2 \% \text {, water, potatoes } 16 \% \text {, rabbit meat without } \\
\text { decoction } 9 \% \text {, corn starch, celery } 2.5 \% \text {, soybean oil }\end{array}$ & H1 & $\begin{array}{l}\text { 3/4th of glass of chopped vegetables: carrot, potato, celery, } 250 \\
\text { ml of water, } 1 \text { spoon of precooked rabbit meat without } \\
\text { decoction, } 1 \text { spoon of butter, } 2 \text { spoons of corn cereal }\end{array}$ \\
\hline $\mathrm{C} 2$ & $\begin{array}{l}\text { carrot, water, potatoes, turkey meat without decoction, } \\
\text { peas, gluten-free wheat starch, pore, soybean oil }\end{array}$ & $\mathrm{H} 2$ & $\begin{array}{l}1 \text { middle-sized carrot, } 1 / 2 \text { middle-sized potato, small piece of } \\
\text { parsley, } 1 \text { spoon of separately cooked turkey meat without } \\
\text { decoction }\end{array}$ \\
\hline C3 & $\begin{array}{l}\text { water, carrot } 28 \% \text {, potatoes } 15.7 \% \text {, rice } 10.3 \% \text {, chicken } \\
\text { meat without decoction } 9 \% \text {, celery } 1.8 \% \text {, soybean oil }\end{array}$ & H3 & $\begin{array}{l}\text { One small carrot, one small potato, a piece of parsley, } 250 \mathrm{~mL} \\
\text { of water, one spoon of separately cooked chicken meat without } \\
\text { decoction, one spoon of soybean oil }\end{array}$ \\
\hline $\mathrm{C} 4$ & $\begin{array}{l}\text { water, carrot } 29 \% \text {, potatoes } 17 \% \text {, gluten-free wheat starch, } \\
\text { pore } 2.5 \% \text {, soybean oil }\end{array}$ & H4 & $\begin{array}{l}3 / 4 \text { glass of chopped vegetables: carrot, potato, parsley, celery, } \\
\text { a spoon of butter, } 250 \mathrm{~mL} \text { of water }\end{array}$ \\
\hline C5 & $\begin{array}{l}\text { potato } 31 \% \text {, spinach } 30 \% \text {, skimmed milk } 29 \% \text {, water, } \\
\text { cream } 3 \% \text {, rapeseed oil } 1.3 \%\end{array}$ & H5 & $\begin{array}{l}\text { One middle-sized potato, } 15 \text { spinach leafs, one little spoon of } \\
\text { fresh butter, } 100 \mathrm{~mL} \text { of water }\end{array}$ \\
\hline
\end{tabular}


methodology of AOAC was used. Results are expressed as $\mathrm{mg} / \mathrm{kg}$ fresh weight of the sample. The analysis was performed following colorimetric procedure and measuring intensity of the color produced through the reaction between nitrites ions with Griess reagent. Nitrates were earlier reduced to nitrites with the use of powdered cadmium [12]. All the analyses were made in three replications.

\subsection{Statistical Methods}

Experimental data were subjected to one-factor analysis of variance (ANOVA) in order to determine statistical differences between mean values. Also the Games Howell's multiple comparison post-hoc tests were carried.

The statistical significance level was set at $p<0.05$ (results with $\mathrm{p}$ values less than 0.05 were considered as statistically significant). Calculations were performed with statistical software package SPSS Statistics 14.0.

\subsection{Estimation of Infants' Dietary Exposure}

To estimate infants' dietary exposure to nitrates and nitrites, mean values of their concentration in a meal portion were compared with acceptable daily intake for an average 6-months old baby of body weight (bw)
8 kilograms.

\section{Results and Discussion}

\subsection{Concentration of Nitrates and Nitrites}

Nitrites content in all the samples was below the detection limit of applied method $(<0.9 \mathrm{mg} / \mathrm{kg})$. Consequently nitrites levels comparison was not possible. Although even if considering nitrites amount of $0.9 \mathrm{mg} / \mathrm{kg}$ in a meal, a 200-gram portion would contain $0.18 \mathrm{mg}$ of nitrites. According to ADI of $0-0.07 \mathrm{mg} / \mathrm{kg} \mathrm{bw} /$ day [13], a daily limit to an $8 \mathrm{~kg}$ baby amounts $0.56 \mathrm{mg}$ of nitrites. Therefore according to legislation limits levels below $0.9 \mathrm{mg} / \mathrm{kg}$ consist of values below $32 \%$ of ADI and examined foods can be perceived as safe.

Average concentrations of nitrates in all samples are summarized in Fig. 1. Values obtained varied considerably according to the composition and type of the meal.

Nitrates contents in commercial products ranged from $9.1 \mathrm{mg} / \mathrm{kg}$ to $38.1 \mathrm{mg} / \mathrm{kg}$. In homemade meals values extended from $26.6 \mathrm{mg} / \mathrm{kg}$ to $118.8 \mathrm{mg} / \mathrm{kg}$ being much more diversified than in jarred foods. Levels in all samples were lower than legislation limit of $200 \mathrm{mg} / \mathrm{kg}$ [14].

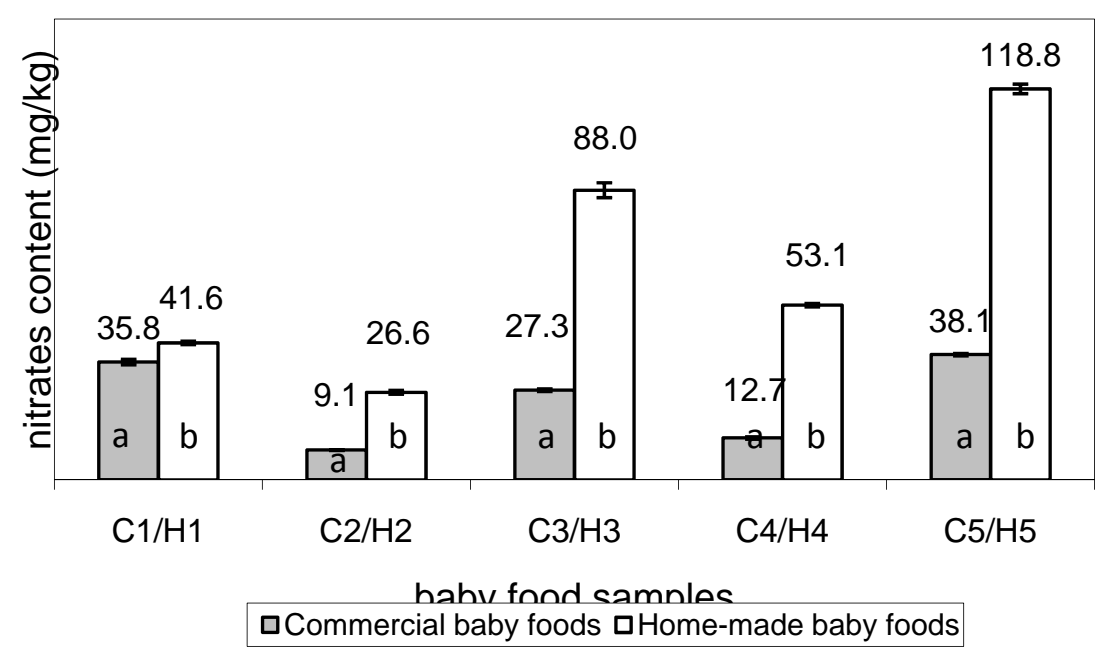

Fig. 1 Mean nitrates content results in examined baby foods (mg/kg).

Error bar represents standard deviation. Different lower-case letters ( $a$ and $b$ ) indicate significant differences (one-way ANOVA test $p<0.05$ ) between commercial and homemade meals. 
Both within commercial alike in homemade foods maximum contents of nitrates were found for the meal number 5 (potatoes and spinach). This is consistent with common observation that spinach is classified as one of the most nitrates-accumulating vegetable, causing health risks for infants [15]. Study's investigation revealed that homemade variant of spinach-potato dish contained approximately 3 times more nitrates than its commercial counterpart.

Comparison of nitrates contents revealed visible differences between both types of foods in favor of the industrially produced ones. The most significant difference was observed between jarred vegetable $\mathrm{C} 4$ meal and its homemade equivalent H4. In the latter one nitrates content of $53.1 \mathrm{mg} / \mathrm{kg}$ appeared to be 4-times higher than in its commercial counterpart: $12.7 \mathrm{mg} / \mathrm{kg}$. In three other variants of: vegetable-turkey, vegetable-chicken and pure vegetable meals numbered respectively: 2, 3,5, differences ranged at least 3-times more contents in homemade counterparts. Values in vegetable-rabbit samples $\mathrm{C} 1$ and $\mathrm{H} 1$ did not differ considerably: amounted respectively 35.8 and $41.6 \mathrm{mg} / \mathrm{kg}$.

Mean nitrates content for total commercial samples amounted $24.6 \mathrm{mg} / \mathrm{kg}$, while in homemade equivalents: $65.6 \mathrm{mg} / \mathrm{kg}$. Comparison of nitrates levels of commercial and homemade foods revealed statistically significant differences between the two groups of meals $(p<0.05)$.

Little data regarding nitrates content in homemade baby foods are available. Study carried by Murone et al. in 2005 referred to excess of nitrates in inappropriately stored meals [5]. Current research was carried for freshly-prepared foods therefore is not relevant to compare with the mentioned. This study indicated lower than other authors' concentrations of nitrates in commercial foods: $61-108 \mathrm{mg} / \mathrm{kg}[7,8,10]$.

Results obtained reveal that much attentionis paid to safety of commercial foods. Low values of nitrites and nitrates in those products prove proper selection of raw materials and maintenance of surveillance by authorities.

It is of great interest that the highest levels of nitrates in any investigated meal did not provide more than regulations' limit.

\subsection{Evaluation of Dietary Exposure to Nitrates}

Apart from comparing the concentration of nitrates with the maximum European legislation, significant assessment of potential health hazards for children was obtained by calculating nitrates intake deriving from a portion of a meal and comparing each amount with ADI set by international organizations: for nitrates 0-3.7 $\mathrm{mg} / \mathrm{kg}$ bw/day (Opinion, 2008). According to the FAO/WHO data estimated daily nitrates intake limit for a baby of bw $8 \mathrm{~kg}$ amounts $29.6 \mathrm{mg}$ (indicated as $100 \%$ of ADI on the upper axis in Fig. 2).

According to data of "DONALD" study children aged 6 months ingest daily about 142-203 g of commercial vegetable/meat foods [16]. In this analysis assumption of a $200 \mathrm{~g}$ portion was taken into consideration. Fig. 2 presents results of a 6-months old infant's exposure scenario to nitrates from investigated meals.

Although any of determined nitrates content wasn't near legislation limit, some alarming issues can be observed within obtained percentage values of ADI for homemade foods. In particular attention should be paid to results of vegetable-chicken H3 (59.5\% ADI) and potato-spinach meal H5 (80.3\% ADI). Results for the rest of homemade meals amounted $18 \%-35.9 \%$ of ADI. Values obtained for commercial products: 6\%-25.7\% did not approach high levels of ADI for considered child's age.

Ingestion none of a single $200 \mathrm{~g}$ portion of examined meal would have been cause of exceeding ADI. Nevertheless problem can occur when consuming more servings per day, which contain comparable to homemade meal of vegetable-chicken H3 and potato-spinach H5 quantities of nitrates. Daily intake of around $336 \mathrm{~g}$ of H3 and $250 \mathrm{~g}$ of H5 could 


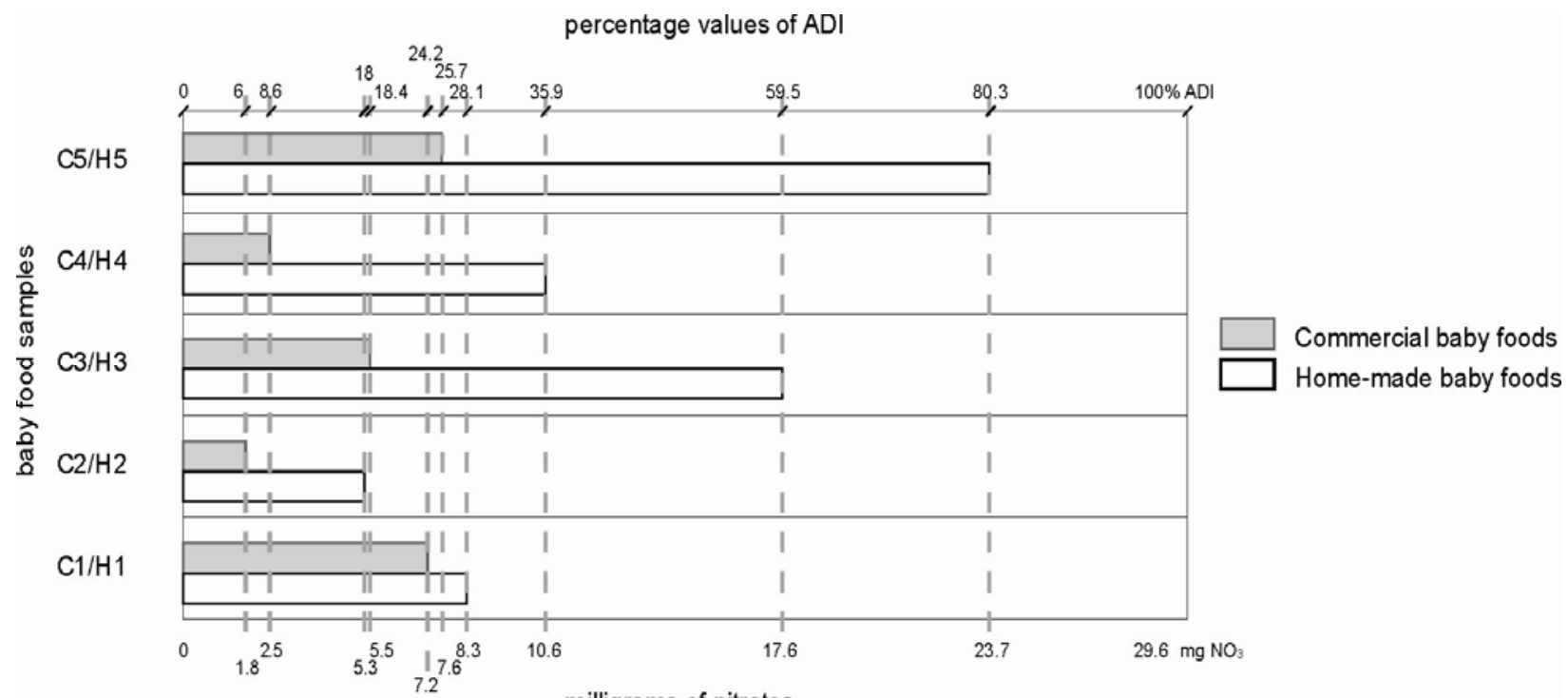

Fig. 2 Estimation of the nitrates intake through investigated baby foods consumption based on the mean concentrations found in the study.

Lower axis: $\mathrm{mg}$ of nitrates provided to an infant ingesting a $200 \mathrm{~g}$ serving of a meal.

Upper axis: results reflected as percentage values of ADI.

induce toxic effects in infant. Those estimated exposures are most likely to be of health concern. Total degree of risk depends not only on intake of these food products, but also overall dietary nitrates intake aside from other sources. Except vegetable also fruit-based and cereal foods have been reported as nitrates source. In case of non-breastfed infants-reconstitution of powdered milk with water may additionally raise nitrates content in their daily diet [17]. Fragility of infants requires special care about food choices destined for them. With long-term daily ingestion of high-nitrates foods the risk of mild to moderate methemoglobinemia would be increased.

Levels of nitrates found in homemade spinach meal reveal that its consumption should be carried with caution in little infants. In its relation to much more safe levels in equivalent commercial product, parents should consider frequency of feeding with homemade spinach meals. Levels of nitrates indicated in homemade vegetable-chicken meal are also disquieting.

\section{Conclusion}

Significant differences between commercial and homemade baby foods in nitrates levels were obtained. Investigated commercial foods appear to be less contaminated with nitrates when compared to their homemade counterparts. Evaluation of dietary exposure does not raise any doubts in potential danger. In turn: case of some homemade equivalents' nitrates contents, even though less than legislation limit appears to be alarming.

Study's data draw important conclusion: decisions about weaning foods should be based on the knowledge about critical points in the selection of homemade meals' ingredients. Findings imply that formulation of infant's diet only on homemade foods at the beginning of weaning period could impose danger in exceeding nitrates levels. This issue merits further research involving homemade foods composed of ingredients originating from different sources and with a comprehensive and well-defined sample to analyze the complete weaning diet of infants and to enable discussion on factors contributing to the nitrates contents in the weaning diet in more depth.

\section{References}

[1] World Health Organization: WHO. 2003. Library 
Cataloguing-in-Publication Data. Global Strategy for Infant and Young Child Feeding. http://www.who.int/nutrition/publications/gs_infant_feedi ng_text_eng.pdf.

[2] Directive 2006/125/EC of 5 December 2006 on processed cereal-based foods and baby foods for infants and young children.

http://eur-lex.europa.eu/legal-content/EN/ALL/?uri=CEL EX\%3A32006L0125.

[3] Hilbig, A., Foterek, K., Kersting, M., and Alexy, U. 2015. "Home-made and Commercial Complementary Meals in German Infants: Results of the DONALD Study." Journal of Human Nutritionand Dietetics 28: 613-22.

[4] Sanchez-Echaniz, J., Benito-Fernandez, J., and Mintegui-Raso, S. 2001. "Methemoglobinemia and Consumption of Vegetables in Infants." Pediatrics 107 (5): 1024-8.

[5] Murone, A. J., Stucki, P., Roback, M. G., and Gehri, M. 2005. "Severe Methemoglobinemia due to Food Intoxication in Infants." Pediatric Emergency Care 21: 536-8.

[6] Bona, A. 2010. "Traditional versus Manufactured Baby Food: Research on Mothers' Preferences." Current Trends in Commodity Science. Market Research 15: 37-46.

[7] Cortesi, M. L., Vollano, L., Peruzy, M. F., Marrone, R., and Mercogliano, R. 2015. "Determination of Nitrates and Nitrites Levels in Infant Foods Marketed in Southern Italy." CyTA-Journal of Food 13 (4): 629-34.

[8] Rebelo, J. S., Almeida, M. D., Vales, L., and Almeida Cristina, M. M. 2015. "Presence of Nitrates in Baby Foods Marketed in Portugal." Cogent Food \& Agriculture. Food Science and Technogoly 1: 1010414.

[9] Özdestan, O., and Uren, A. 2012. "Nitrates and Nitrites Contents of Baby Foods.” AkademikGida/Academic Food Journal 10 (4): 11-8.

[10] Vasco, E., and Alvito, P. 2011. "Occurrence and Infant Exposure Assessment of Nitrates in Baby Foods Marketed in the Region of Lisbon, Portugal." Food Additives and Contaminants Part B 4 (3): 218-25.
[11] De Martin, S., and Restani, P. 2003. "Determination of Nitrates by Novel Ion Chromatographic Method: Occurrence in Leaky Vegetables (Organic and Conventional) and Exposure Assessment for Italian Consumers." Food Additives and Contaminants 20: 787-92.

[12] AOAC. 1995. "Official Methods of Analysis." 12th ed. Washington, DC.

[13] European Food Safety Authority: EFSA. 2008. Opinion of the Scientific Panel on Contaminants in the Food Chain on A Request from the European Commission to Perform A Scientific Risk Assessment on Nitrates in Vegetables (Question No. EFSA-Q-2006-071). Accessed April 10, 2008.

http://www.efsa.europa.eu/sites/default/files/scientific_ou tput/files/main_documents/689.pdf.

[14] Commission Regulation (EC), No. 1881/2006, Setting Maximum Levels for Certain Contaminants in Foodstuffs. Accessed December 19, 2006.

[15] European Food Safety Authority: EFSA, 2010. Panel on Contaminants in the Food Chain (CONTAM), Scientific Opinion on Possible Health Risks for Infants and Young Children from the Presence of Nitrates in Leafy Vegetables (Question No. EFSA-Q-2010-01037). Accessed December 2010. http://onlinelibrary.wiley.com/doi/10.2903/j.efsa.2010.19 35/epdf.

[16] Kersting, M., Alexy, U., Sichert-Hellert, W., Manz, F., and Schoch, G. 1998. "Measured Consumption of Commercial Infant Food Products in German Infants: Results from the DONALD study. Dortmund Nutritional and Anthropometrical Longitudinally Designed." Journal of Pediatric and Gastroenterology Nutrition 27 (5): 547-52.

[17] Śmiechowska, M., Usama El-Sayed, M., and NewerliGuz, J. 2001. "Determination of Nitrates and Nitrites in Selected Commercial Infant Food Products Available on Polish and Egyptian Markets." Egyptian Journal of Nutrition 16 (1): 63-81. 